\title{
Hydrogenation of sugars to sugar alcohols in the presence of a recyclable
}

\section{$\mathrm{Ru} / \mathrm{Al}_{2} \mathrm{O}_{3}$ catalyst commercially available}

Isaline Bonnin, ${ }^{a}$ Raphaël Méreau, ${ }^{b}$ Thierry Tassaing, ${ }^{b}$ François Jérome and Karine De Oliveira Vigier ${ }^{\mathrm{a},{ }^{*}}$

a IC2MP UMR CNRS 7285 Université de Poitiers, 1 rue Marcel Doré, 86073 Poitiers Cédex 09

${ }^{\mathrm{b}}$ ISM, UMR 5255 CNRS-Université de Bordeaux, 351 cours de la libération, 33405 Talence Cedex.

Pages S1-S14

Fig. S1. Pictures of the reactor (Multiple Reactor System Series 5000 by Paar Instrument Company) used for hydrogenation reaction.

Fig. S2. Scheme of procedure reduction of $\mathrm{Ru} / \mathrm{Al}_{2} \mathrm{O}_{3}$ catalyst before catalytic tests. $\mathrm{He}$ and $\mathrm{H}_{2}$ were continuously added at $2 \mathrm{~L} / \mathrm{h}$.

Fig. S3. Stirring effect of the hydrogenation of glucose in presence of $\mathrm{Ru} / \mathrm{Al}_{2} \mathrm{O}_{3}$ under 30 bar of $\mathrm{H}_{2}$ at $120^{\circ} \mathrm{C}$ for $2 \mathrm{~h}$.

Fig. S4. Repartition products after the hydrogenation of glucose in presence of $\mathrm{Ru} / \mathrm{Al}_{2} \mathrm{O}_{3}$ under $30 \mathrm{bar}$ of $\mathrm{H}_{2}$ at $120^{\circ} \mathrm{C}$ during variable reaction time.

Fig. S5. Chromatogram profiles and peak identification of glucose hydrogenation in presence of $\mathrm{Ru} / \mathrm{Al}_{2} \mathrm{O}_{3}$ under 30 bar of $\mathrm{H}_{2}$ at $120^{\circ} \mathrm{C}$ for variable reaction time. Blank sample corresponds to water injection.

Fig. S6. Chromatogram profiles and peak identification of glucose hydrogenation in presence of $\mathrm{Ru} / \mathrm{Al}_{2} \mathrm{O}_{3}$ at $120^{\circ} \mathrm{C}$ for $2 \mathrm{~h}$ with variable $\mathrm{H}_{2}$ pressure. Peak at 19 min corresponds to a blank peak.

Fig. S7. Recycling experiments of hydrogenation of glucose in presence of both $\mathrm{Ru} / \mathrm{Al}_{2} \mathrm{O}_{3}$ reduced and non-reduced under 30 bar of $\mathrm{H}_{2}$ at $120^{\circ} \mathrm{C}$ for $1 \mathrm{~h} 30$.

Fig S8. Isotherm linear plot of reduced and spent $\mathrm{Ru} / \mathrm{Al}_{2} \mathrm{O}_{3}$ catalyst.

Fig. S9. TGA analysis of a) reduced $\mathrm{Ru} / \mathrm{Al}_{2} \mathrm{O}_{3}$ under $\mathrm{H}_{2}$ for $2 \mathrm{~h}$ at $200^{\circ} \mathrm{C}$ and b) spent $\mathrm{Ru} / \mathrm{Al}_{2} \mathrm{O}_{3}$ catalyst after 3 runs of hydrogenation. Full lines and dotted lines are respectively related to the loss of weight (\%) and the temperature difference $\left({ }^{\circ} \mathrm{C} / \mathrm{mg}\right)$.

Fig. S10. TGA analysis of $\mathrm{Ru} / \mathrm{Al}_{2} \mathrm{O}_{3}$ after extraction of the organic compounds by ethanol.

Fig. S11. XRD profiles of fresh and spent $\mathrm{Ru} / \mathrm{Al}_{2} \mathrm{O}_{3}$ catalyst after further run of hydrogenation of glucose.

Fig. S11. TEM analysis of fresh and spent $\mathrm{Ru} / \mathrm{Al}_{2} \mathrm{O}_{3}$ catalyst.

Fig.S12: extraction of adsorbed compounds with ethanol. ${ }^{1} \mathrm{H}$ NMR analysis.

Fig. S13: extraction of adsorbed compounds with ethyl acetate. ${ }^{1} \mathrm{H}$ NMR analysis.

Fig. S14: extraction of adsorbed compounds with acetone. ${ }^{1} \mathrm{H}$ NMR analysis.

Fig. S15: extraction of adsorbed compounds with heptane. ${ }^{1} \mathrm{H}$ NMR analysis.

Fig. S16. Comparison of NMR profiles between pure galactitol (red) and solid product obtained after hydrogenation of galactose in presence of $\mathrm{Ru} / \mathrm{Al}_{2} \mathrm{O}_{3}$ under 30 bar of $\mathrm{H}_{2}$ at $120^{\circ} \mathrm{C}$ for $2 \mathrm{~h}$ (green).

Table S1. Weight percentage of the metal determined by ICP-OES analysis.

Table S2. BET surface, pore volume and pore size of reduced and spent $\mathrm{Ru} / \mathrm{Al}_{2} \mathrm{O}_{3}$ catalyst. 


\section{Table of contents}

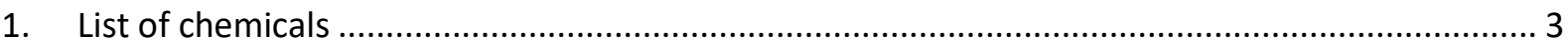

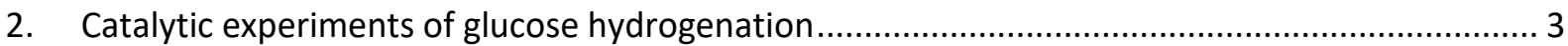

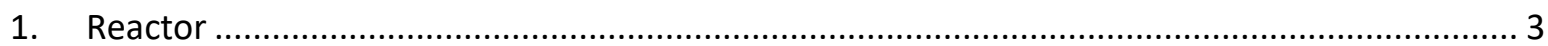

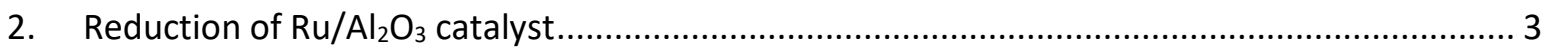

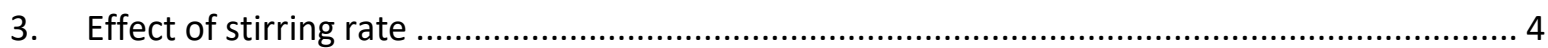

4. Repartition of produced carbohydrates according to time …................................................. 5

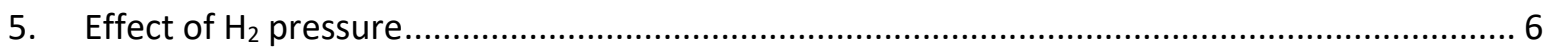

6. Recylcing experiment with reduced and non-reduced catalyst............................................. 6

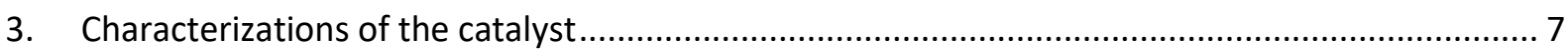

1. Inductively Coupled Plasma Optical Emission Spectrometry (ICP OES) …............................... 7

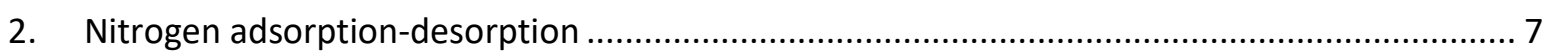

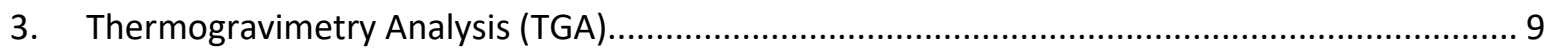

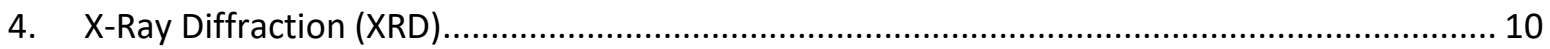

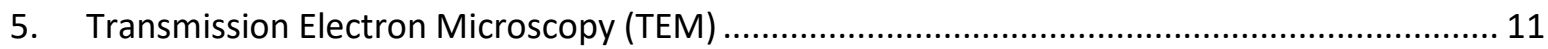

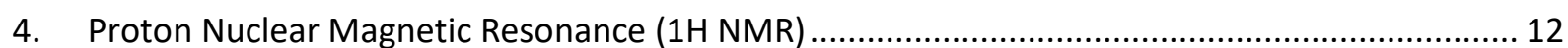

1. Extracted compounds of spent catalyst with organic solvents........................................... 12

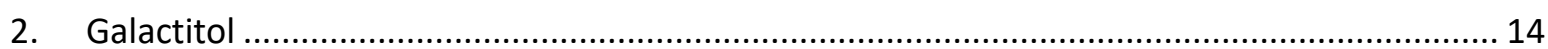




\section{List of chemicals}

D-glucose ( $\geq 99.5 \%$, Sigma-Aldrich), D-fructose ( $\geq 99 \%$, Sigma-Aldrich), D-mannose ( $\geq 99 \%$, SigmaAldrich), D-galactose (99+ \%, Acros Organics), D-xylose ( $\geq 99 \%$, Sigma-Aldrich), D-sorbitol ( $\geq 98 \%$, Sigma-Aldrich), D-mannitol ( $\geq 98 \%$, Sigma-Aldrich), D-galactitol (99\%, Alfa aeser), D-xylitol (Carbosynth), 5 wt. \% Pt/Al $\mathrm{O}_{3}$ (Solvay, Shanghai), 5 wt. \% Pd/Al ${ }_{2} \mathrm{O}_{3}$ (Solvay, Shanghai), 5 wt. \% Ru/Al $\mathrm{O}_{3}$ (Alfa Aeser), methanol LC-MS (Carlo Erba), glacial acid acetic (Carlo Erba), $\mathrm{D}_{2} \mathrm{O}$ (Sigma-Aldrich), DMSO (Sigma-Aldrich), MilliQ ultra-pure water.

\section{Catalytic experiments of glucose hydrogenation}

\section{Reactor}
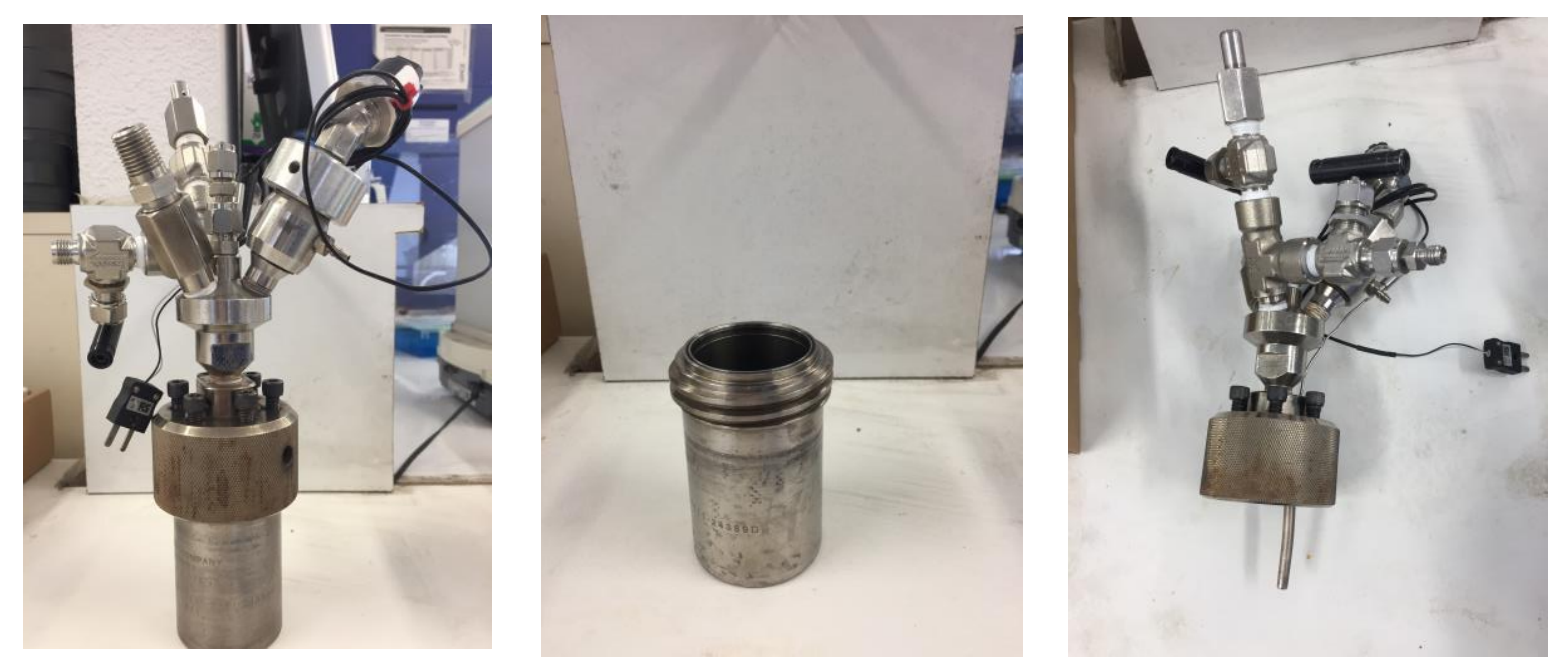

Fig. S1. Pictures of the reactor (Multiple Reactor System Series 5000 by Paar Instrument Company) used for hydrogenation reaction.

The reactor used was a $75 \mathrm{~mL}$ one.

\section{Reduction of $\mathrm{Ru} / \mathrm{Al}_{2} \mathrm{O}_{3}$ catalyst}

The catalyst was reduced under hydrogen/Helium flow as described in Figure S2 Before reaction, catalyst was crushed to break some aggregates. Particles size were heterogeneous. From a known amount of catalyst, $30 \%$ were less than $100 \mu \mathrm{m}, 30 \%$ were comprised between $100 \mu \mathrm{m}$ and $250 \mu \mathrm{m}$, $10 \%$ were comprised between $250 \mu \mathrm{m}$ and $355 \mu \mathrm{m}$ and finally $30 \%$ were bigger than $355 \mu \mathrm{m}$. 

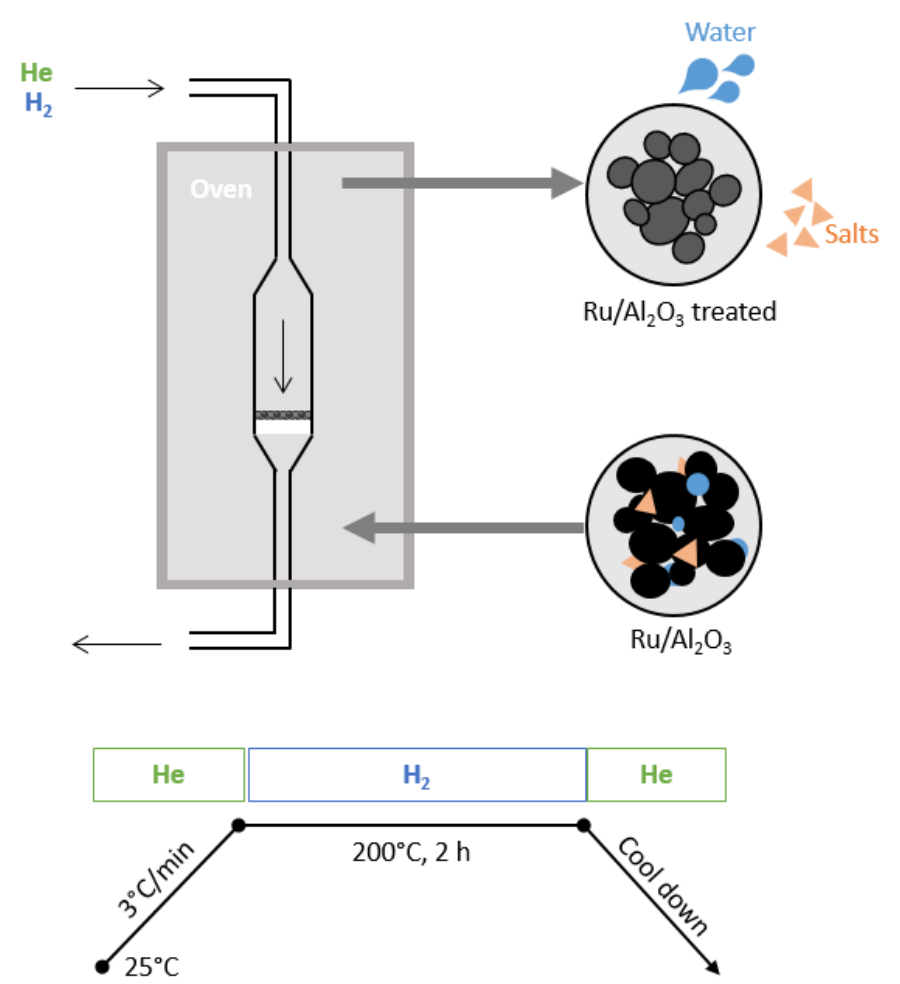

Fig. S2. Scheme of procedure reduction of $\mathrm{Ru} / \mathrm{Al}_{2} \mathrm{O}_{3}$ catalyst before catalytic tests. $\mathrm{He}$ and $\mathrm{H}_{2}$ were continuously added at $2 \mathrm{~L} / \mathrm{h}$.

3. Effect of stirring rate

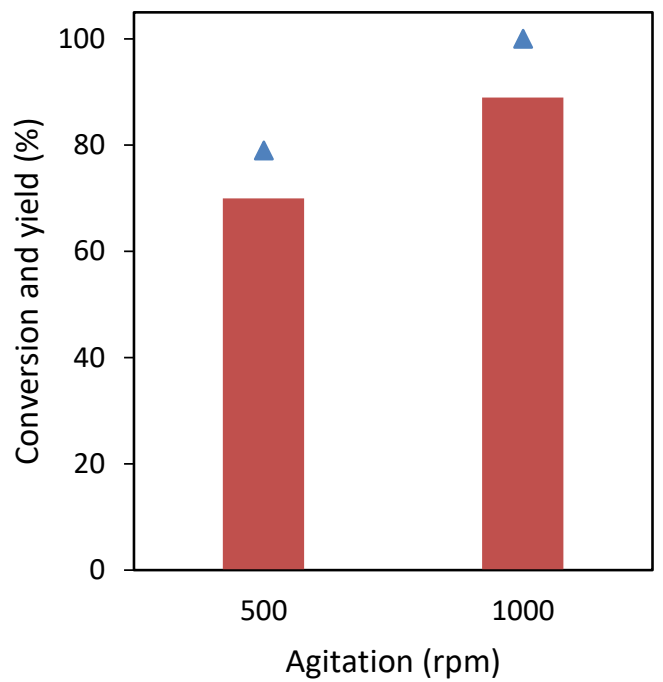

Fig. S3. Stirring effect of the hydrogenation of glucose in presence of $\mathrm{Ru} / \mathrm{Al}_{2} \mathrm{O}_{3}$ under 30 bar of $\mathrm{H}_{2}$ at $120^{\circ} \mathrm{C}$ for $2 \mathrm{~h}$.

The decrease of the stirring rate from $1000 \mathrm{rpm}$ to $500 \mathrm{rpm}$ led to a decrease of the glucose conversion from $100 \%$ to $79 \%$ with a selectivity to sorbitol of $89 \%$. These results show that by having a stirring rate of $1000 \mathrm{rpm}$, the mass transfer was limited. 
4. Repartition of produced carbohydrates according to time

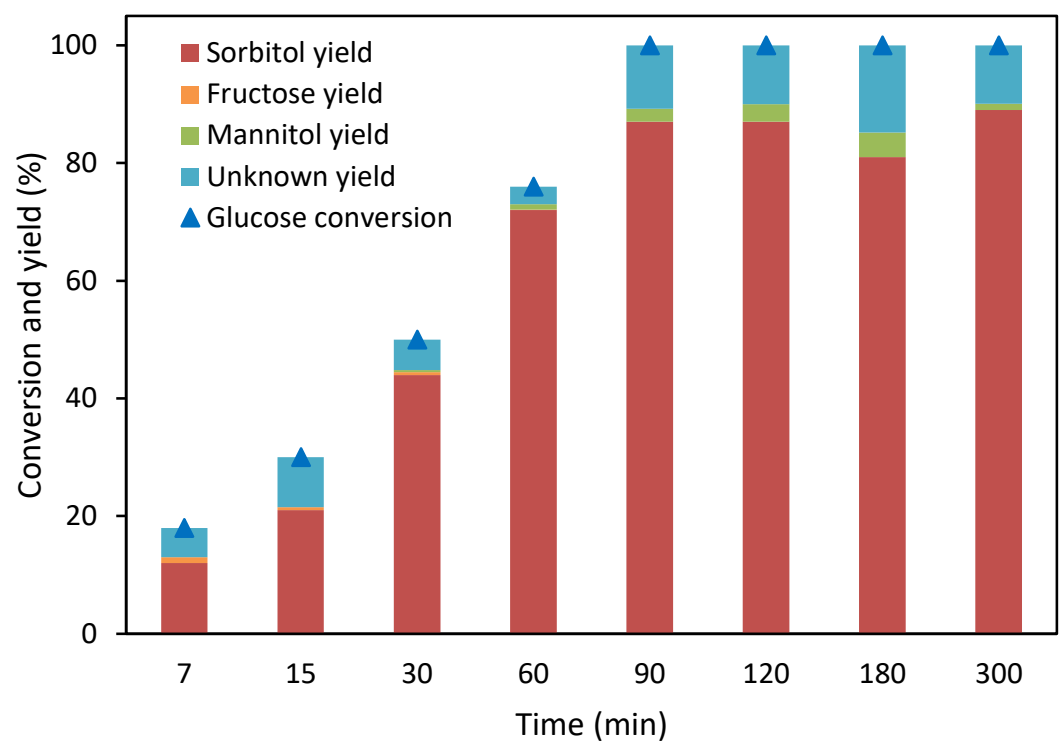

Fig. S4. Repartition products after the hydrogenation of glucose in presence of $\mathrm{Ru} / \mathrm{Al}_{2} \mathrm{O}_{3}$ under 30 bar of $\mathrm{H}_{2}$ at $120^{\circ} \mathrm{C}$ during variable reaction time. Unknown yield corresponds to non-identified (and traces of iditol from $90 \mathrm{~min}$ ).

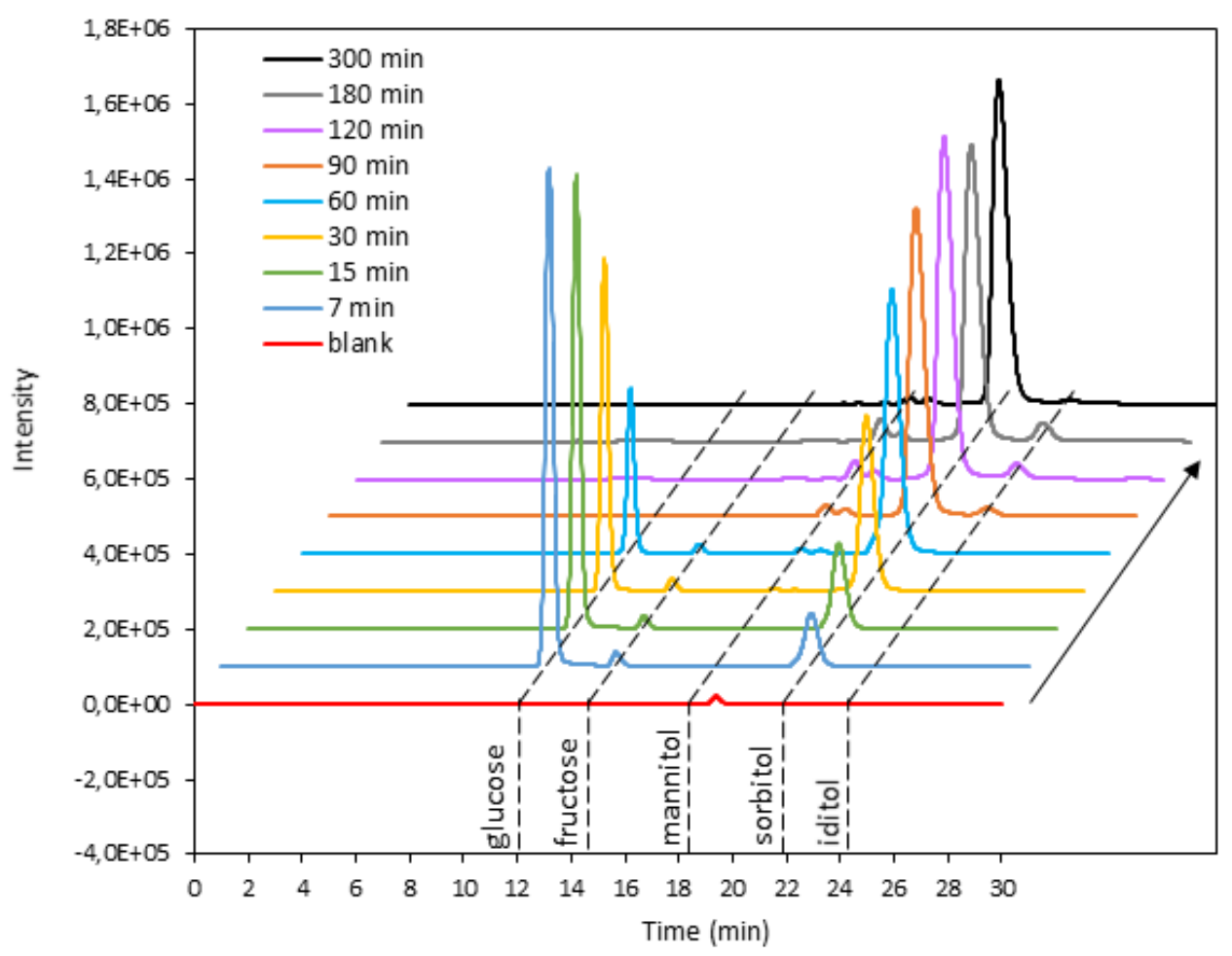

Fig. S5. Chromatogram profiles and peak identification of glucose hydrogenation in presence of $\mathrm{Ru} / \mathrm{Al}_{2} \mathrm{O}_{3}$ under 30 bar of $\mathrm{H}_{2}$ at $120^{\circ} \mathrm{C}$ for variable reaction time. Blank sample corresponds to water injection. 
5. Effect of $\mathrm{H}_{2}$ pressure

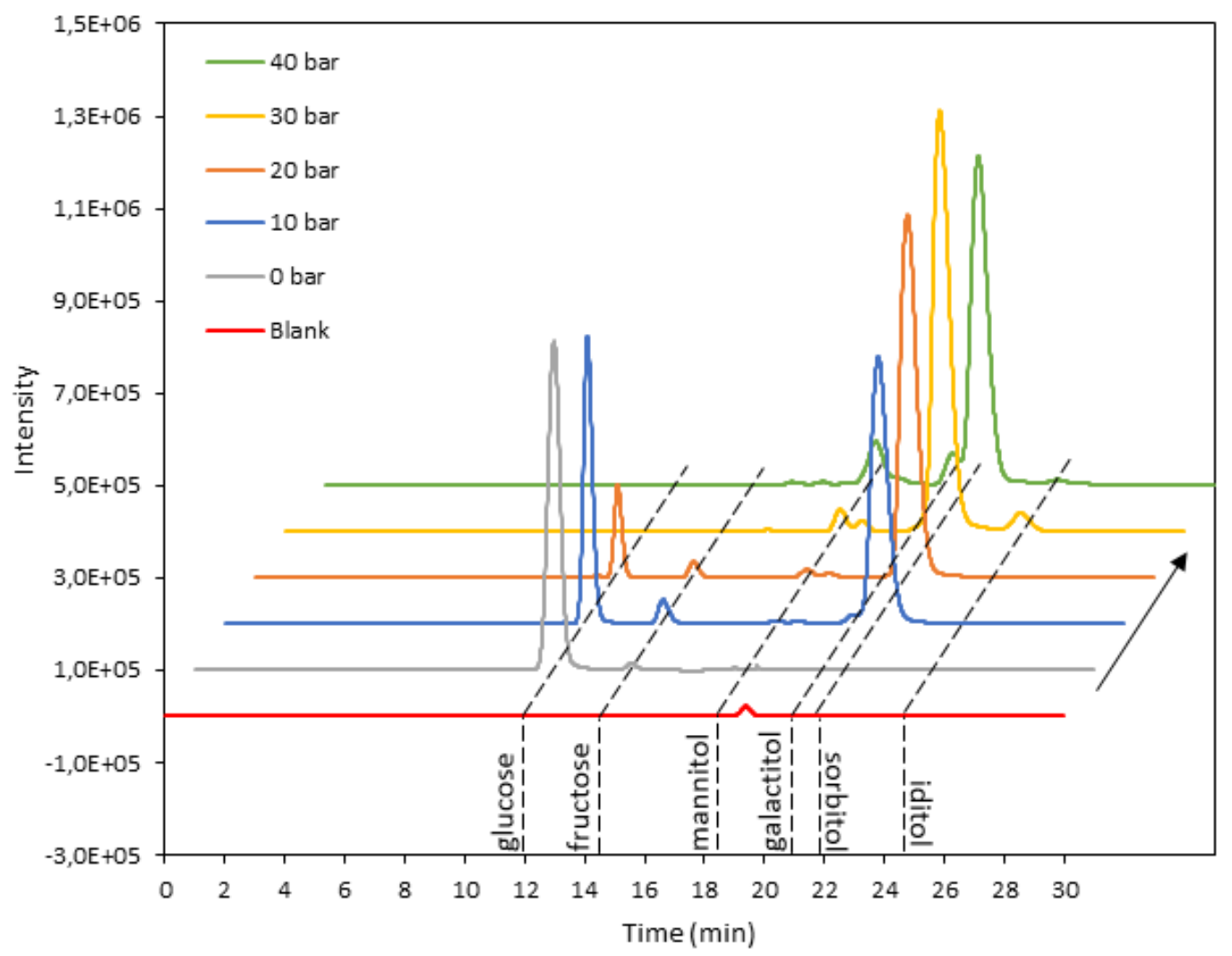

Fig. S6. Chromatogram profiles and peak identification of glucose hydrogenation in presence of $\mathrm{Ru} / \mathrm{Al}_{2} \mathrm{O}_{3}$ at $120^{\circ} \mathrm{C}$ for $2 \mathrm{~h}$ with variable $\mathrm{H}_{2}$ pressure. Peak at 19 min corresponds to a blank peak.

6. Recylcing experiment with reduced and non-reduced catalyst

The recycling of the catalyst was performed as follow: after the first cycle the catalyst was removed by centrifugation. Recovered solid was washed with ethanol and sonicated before centrifugation to remove solvent. This last operation was done at least three time. After drying at $50^{\circ} \mathrm{C}$, the solid was reused for hydrogenation experiments under same experimental conditions and by adjusting glucose ratio and water to the recovered amount of the catalyst. 


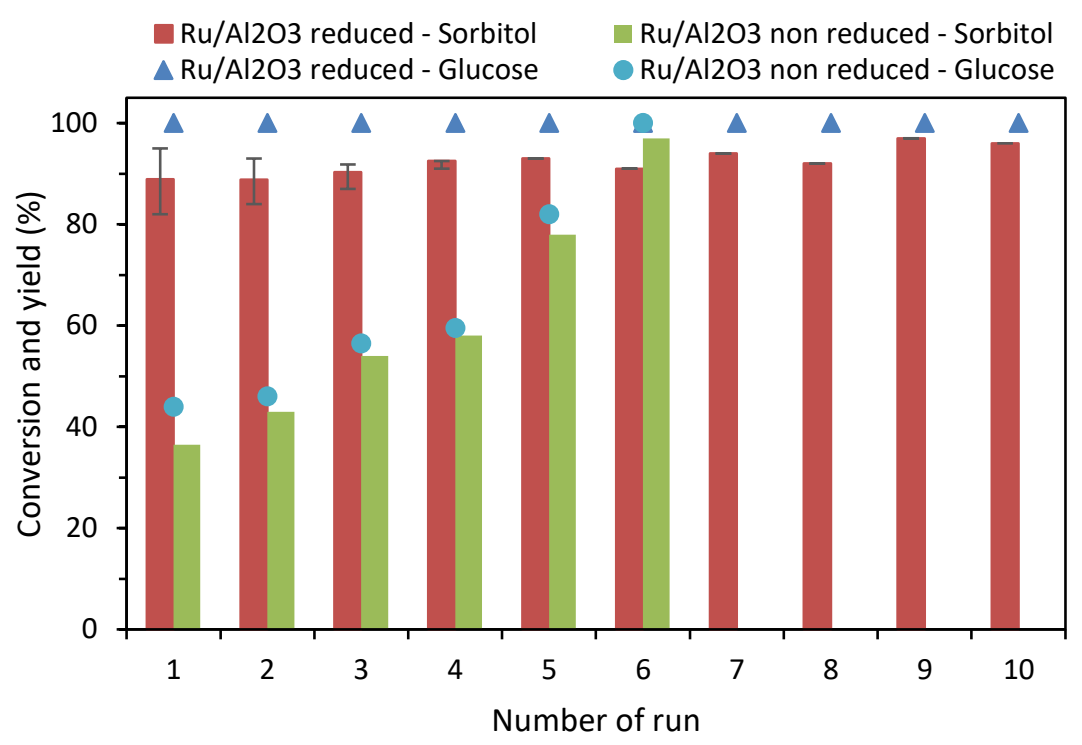

Fig. S7. Recycling experiments of hydrogenation of glucose in presence of both $\mathrm{Ru} / \mathrm{Al}_{2} \mathrm{O}_{3}$ reduced and non-reduced under 30 bar of $\mathrm{H}_{2}$ at $120^{\circ} \mathrm{C}$ for $1 \mathrm{~h} 30$.

\section{Characterizations of the catalyst}

1. Inductively Coupled Plasma Optical Emission Spectrometry (ICP OES)

ICP OES analysis of metal content as well as lixiviated Ru on aqueous phase were executed on an Agilent 5110 VDV. Solid samples were acidified and were mineralized by a micro-wave Anton-Paar Multiwave Pro.

Table S1. Weight percentage of the metal determined by ICP-OES analysis.

\begin{tabular}{lc}
\hline Sample & wt. \% of metal \\
\hline $\mathrm{Ru} / \mathrm{Al}_{2} \mathrm{O}_{3}$ non reduced & 4.4 \\
$\mathrm{Ru} / \mathrm{Al}_{2} \mathrm{O}_{3}$ reduced & 5.3 \\
$\mathrm{Pt} / \mathrm{Al}_{2} \mathrm{O}_{3}$ & 4.3 \\
$\mathrm{Pd} / \mathrm{Al}_{2} \mathrm{O}_{3}$ & 4.7 \\
\hline
\end{tabular}

\section{Nitrogen adsorption-desorption}

Nitrogen adsorption-desorption experiments at $77 \mathrm{~K}$ were performed on a TriStar 3000 instrument to determine specific surface area (by multipoint Brunauer-Emmet-Teller (BET) method). A Micromeritics VacPrep061 was used to eliminate adsorbed water and carbonate impurities by outgassed them at $300^{\circ} \mathrm{C}$ overnight under vacuum. 


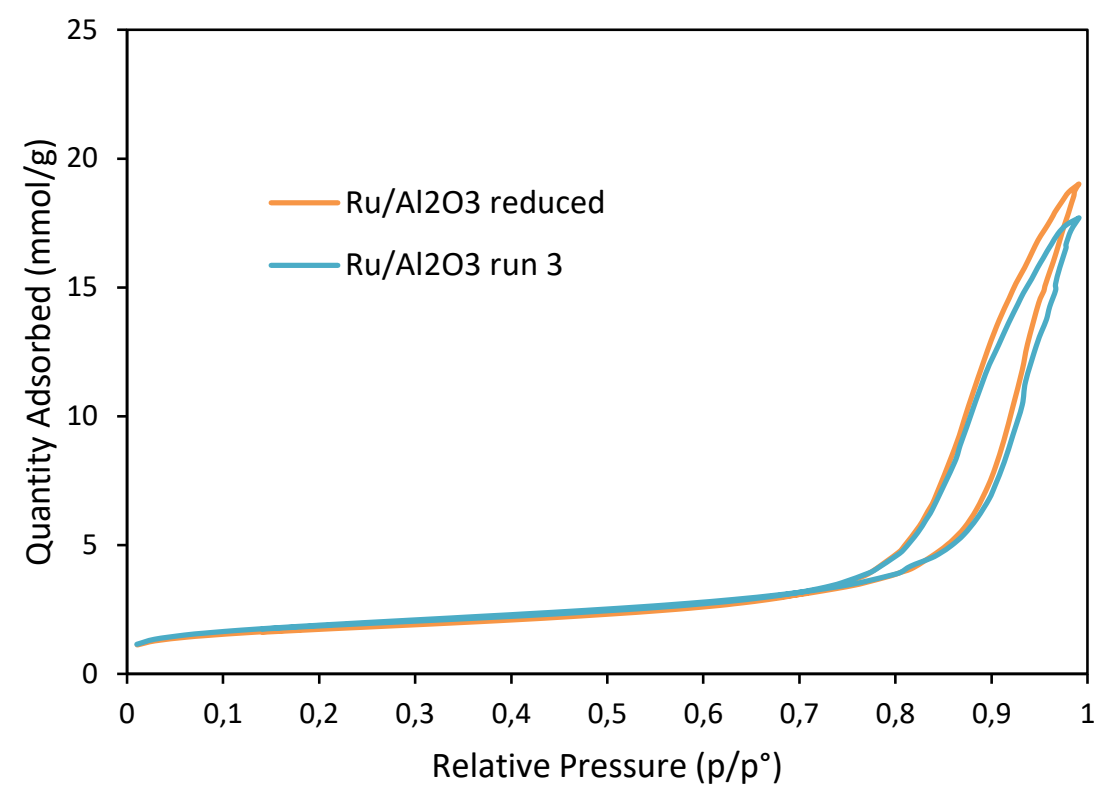

Fig S8. Isotherm linear plot of reduced and spent $\mathrm{Ru} / \mathrm{Al}_{2} \mathrm{O}_{3}$ catalyst.

An isotherm like type $\mathrm{V}$ for the catalyst before and after reaction was observed. The absence of inflexion point at low relative pressure and the hysteresis type $\mathrm{H} 3$ with capillary condensation can confirm that $\mathrm{Ru} / \mathrm{Al}_{2} \mathrm{O}_{3}$ is a mesoporous material (which contains pore size between 2 and $50 \mathrm{~nm}$ ). No significant change of the structure of the catalyst was recorded after three consecutive hydrogenation.

Table S2. BET surface, pore volume and pore size of reduced and spent $\mathrm{Ru} / \mathrm{Al}_{2} \mathrm{O}_{3}$ catalyst.

\begin{tabular}{ccc}
\hline & $\mathrm{Ru} / \mathrm{Al}_{2} \mathrm{O}_{3}$ reduced & $\mathrm{Ru} / \mathrm{Al}_{2} \mathrm{O}_{3}$ after three run \\
\hline BET Surface Area: & $140.3896 \mathrm{~m}^{2} / \mathrm{g}$ & $145.7311 \mathrm{~m}^{2} / \mathrm{g}$ \\
\hline
\end{tabular}

BJH Desorption average pore width

$(4 \mathrm{~V} / \mathrm{A})$

$178.077 \AA$

$166.167 \AA$ 


\section{Thermogravimetry Analysis (TGA)}

TGA analysis of solid samples were carried out on a SDT Q600 TA Instruments under $\mathrm{N}_{2}$ flow and a heating rate of $10^{\circ} \mathrm{C} / \mathrm{min}$.
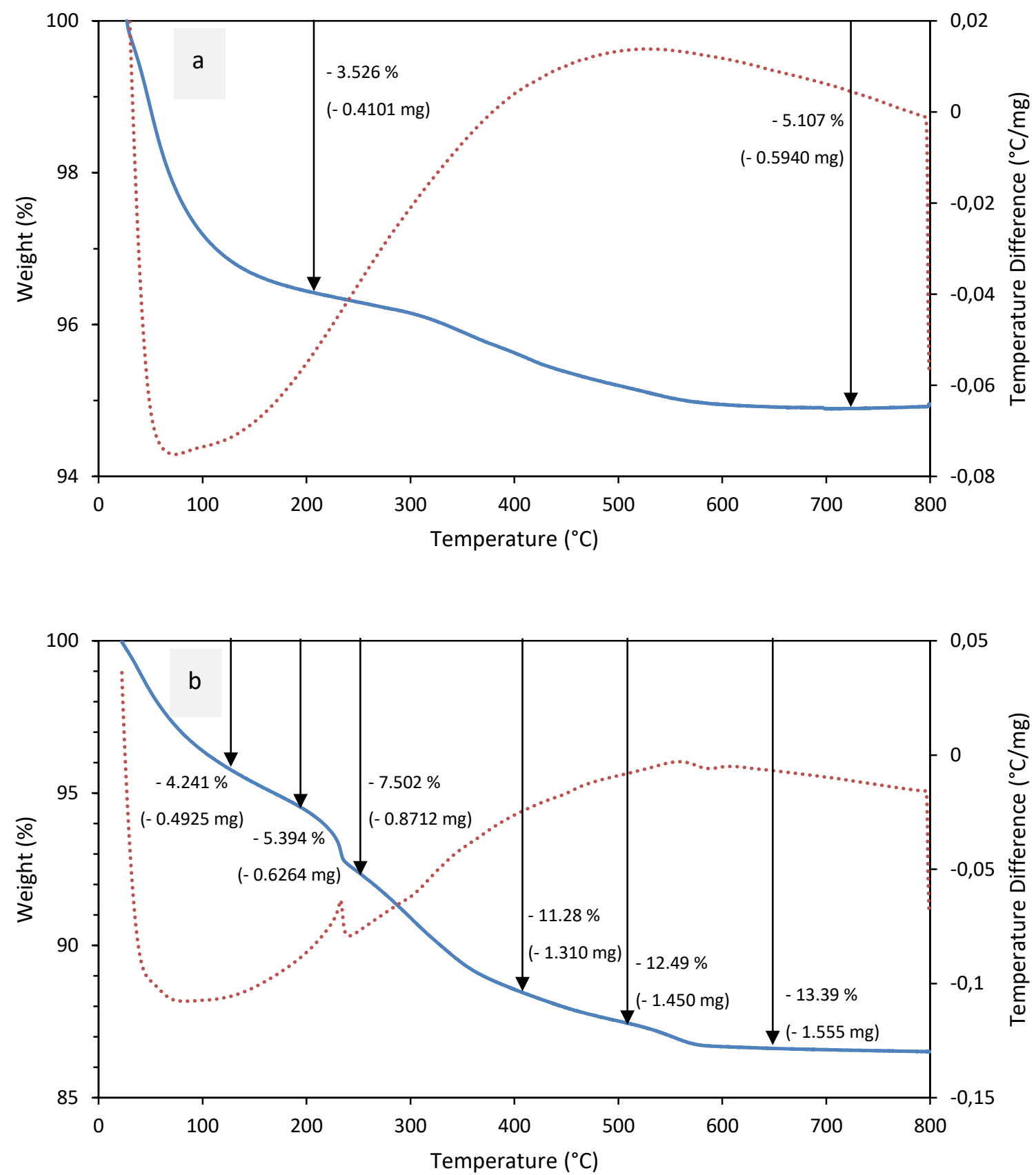

Fig. S9. TGA analysis of a) reduced $\mathrm{Ru} / \mathrm{Al}_{2} \mathrm{O}_{3}$ under $\mathrm{H}_{2}$ for $2 \mathrm{~h}$ at $200^{\circ} \mathrm{C}$ and b) spent $\mathrm{Ru} / \mathrm{Al}_{2} \mathrm{O}_{3}$ catalyst after 3 runs of hydrogenation. Full lines and dotted lines are respectively related to the loss of weight (\%) and the temperature difference $\left({ }^{\circ} \mathrm{C} / \mathrm{mg}\right)$. 
TGA analysis shown that some adsorbed species were observed after reaction. Extractions of adsorbed compounds on surface of spent catalyst were performed using several organic solvents (acetone, ethanol, ethyl acetate and heptane). For each solvent, approximately $11 \mathrm{mg}$ of spent catalyst was extracted three times with $1 \mathrm{~mL}$ of corresponding solvent. All extracted solution were colorless excepted with ethanol. After evaporation of solvent, some products were observed (5 to $10 \mathrm{mg}$ ) and diluted in deutered dimethyl sulfoxide for NMR ${ }^{1} \mathrm{H}$ analysis (see 4.1., Figures S13-S16). A TGA analysis was performed after the extraction with ethanol and $12 \%$ of weight loss was observed, showing that only $1 \%$ of adsorbed compounds were extracted.

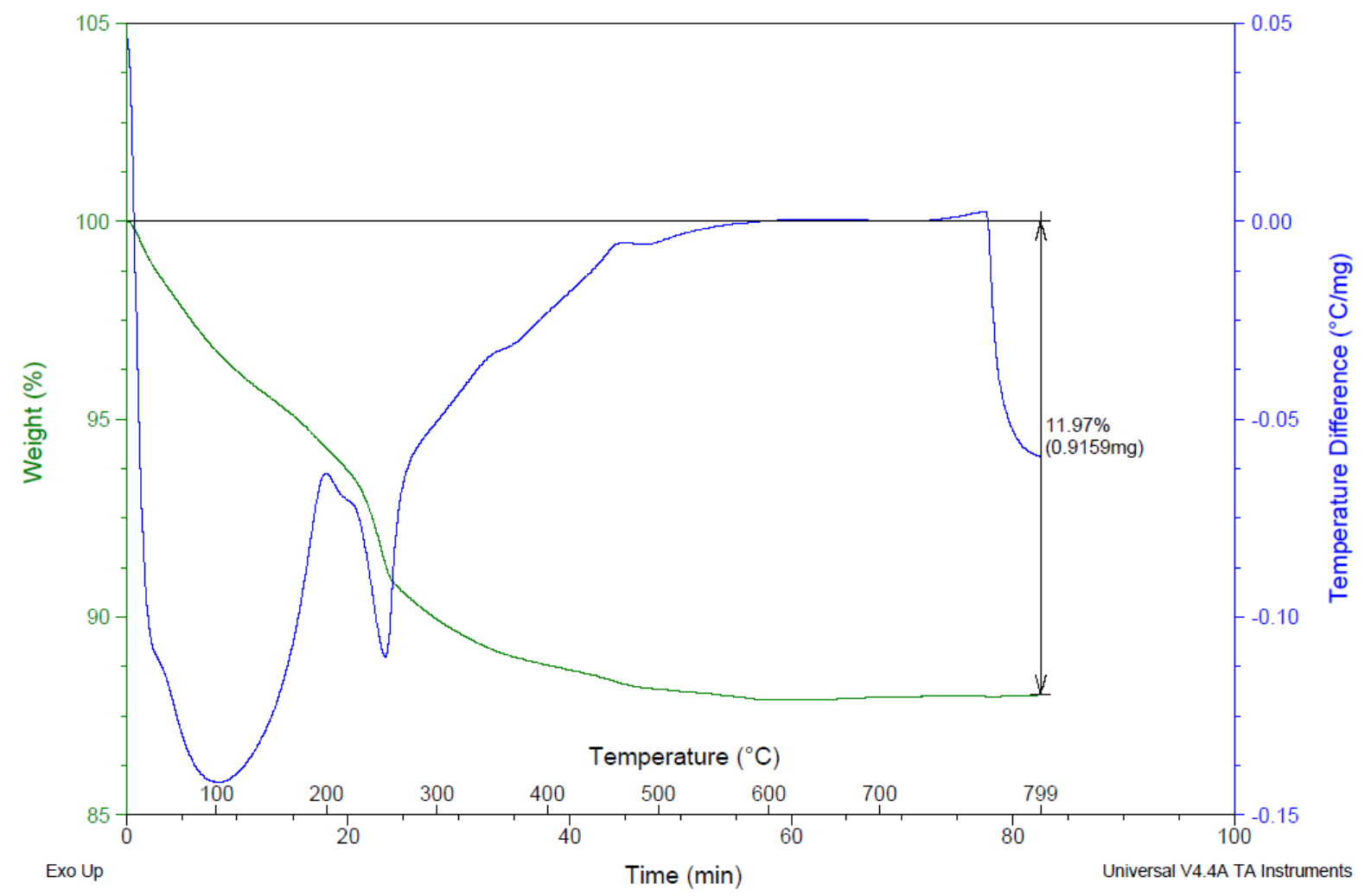

Fig. S10. TGA analysis of $\mathrm{Ru} / \mathrm{Al}_{2} \mathrm{O}_{3}$ after extraction of the organic compounds by ethanol.

\section{X-Ray Diffraction (XRD)}

XRD analysis of solid catalysts were conducted on an EMPYREAN PANalytical Instrument using a $\mathrm{CuK}_{\alpha}$ as a source of radiation and diffractogram profiles were recorded in a range of $10-80^{\circ} 2 \Theta$ every $0.02^{\circ}(2 \Theta)$ step with counting time 2 s per step. 

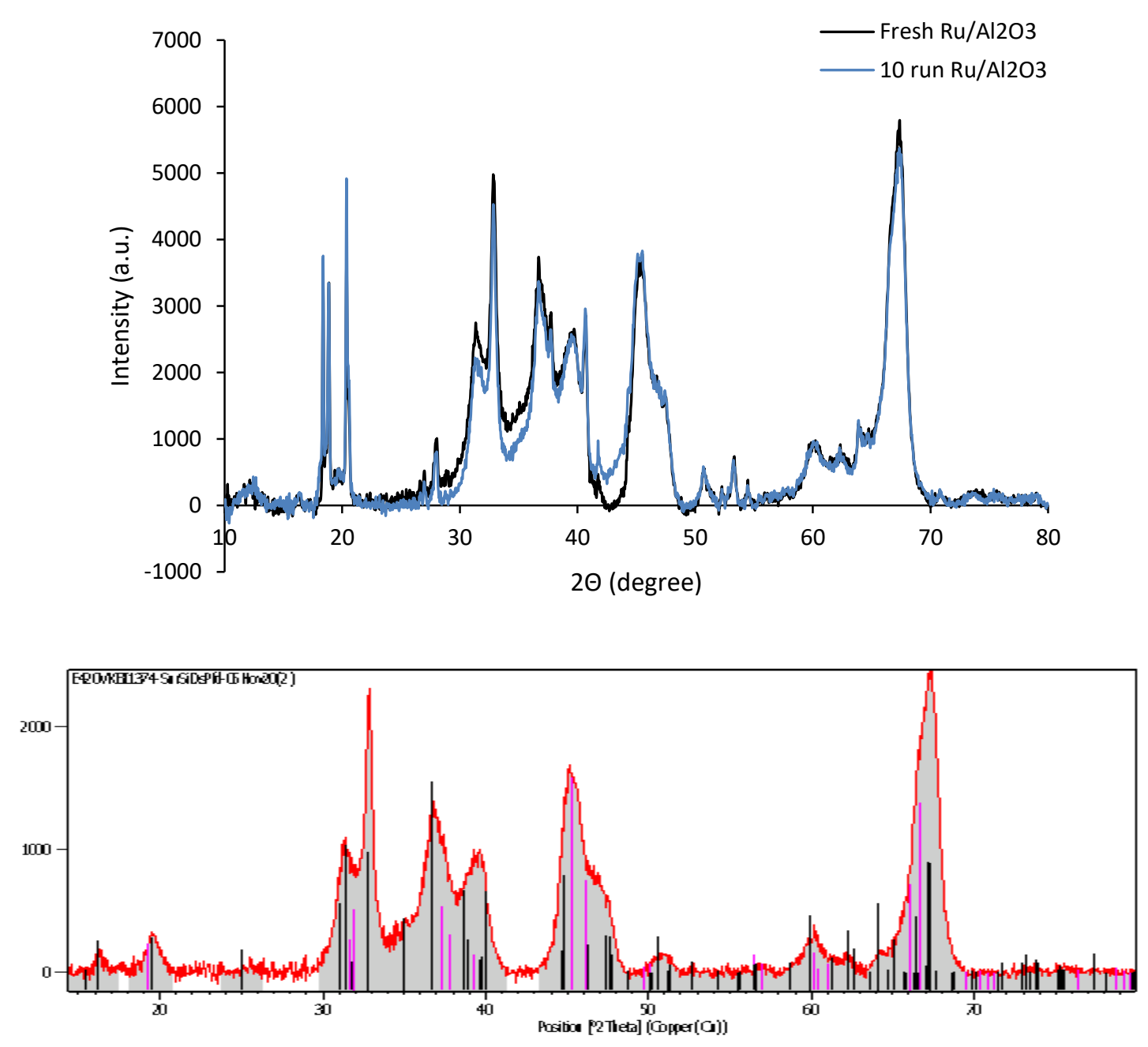

Fig. S11. XRD profiles of fresh and spent $\mathrm{Ru} / \mathrm{Al}_{2} \mathrm{O}_{3}$ catalyst after further run of hydrogenation of glucose.

No change was noticed when fresh and spend catalysts were compared. The support was identified to be a mixture of two phases Aluminium oxide with a monoclinic crystalline structure (JCPDS 98-006-6560, black line) and Gamma Alumina with a tetragonal crystalline phase (JCPDS 98-009-9836 fuchsia line).

\section{Transmission Electron Microscopy (TEM)}

TEM analysis were performed using a JEOL JEM 2100 UHR equipped with a LaB6 filament with a punctual resolution of $0.19 \mathrm{~nm}$. The samples were prepared in ethanol using a sonication bath and some drops were deposited on a carbon grid (Holey Carbon grids). 


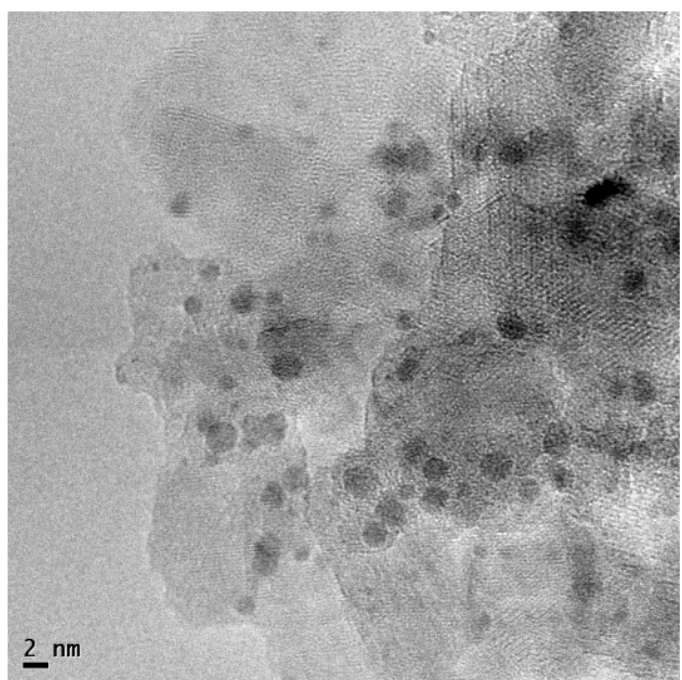

$\mathrm{Ru} / \mathrm{Al}_{2} \mathrm{O}_{3}$ catalyst

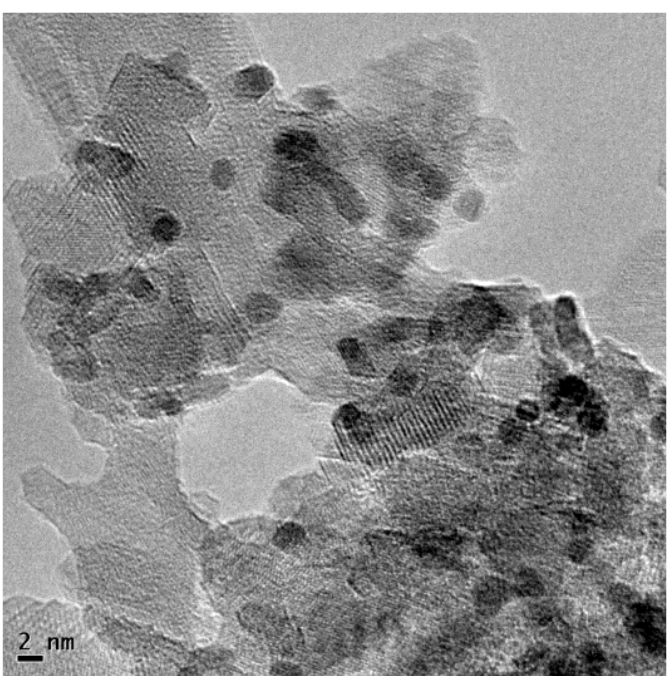

Spent $\mathrm{Ru} / \mathrm{Al}_{2} \mathrm{O}_{3}$ catalyst (after the third run)

Fig. S12. TEM analysis of fresh and spent $\mathrm{Ru} / \mathrm{Al}_{2} \mathrm{O}_{3}$ catalyst.

\section{Proton Nuclear Magnetic Resonance (1H NMR)}

1. Extracted compounds of spent catalyst with organic solvents

${ }^{1} \mathrm{H}$ NMR spectra of extracted compounds were recorded on a Bruker Ultrashield $400 \mathrm{MHz}$ in deutered DMSO solvent.

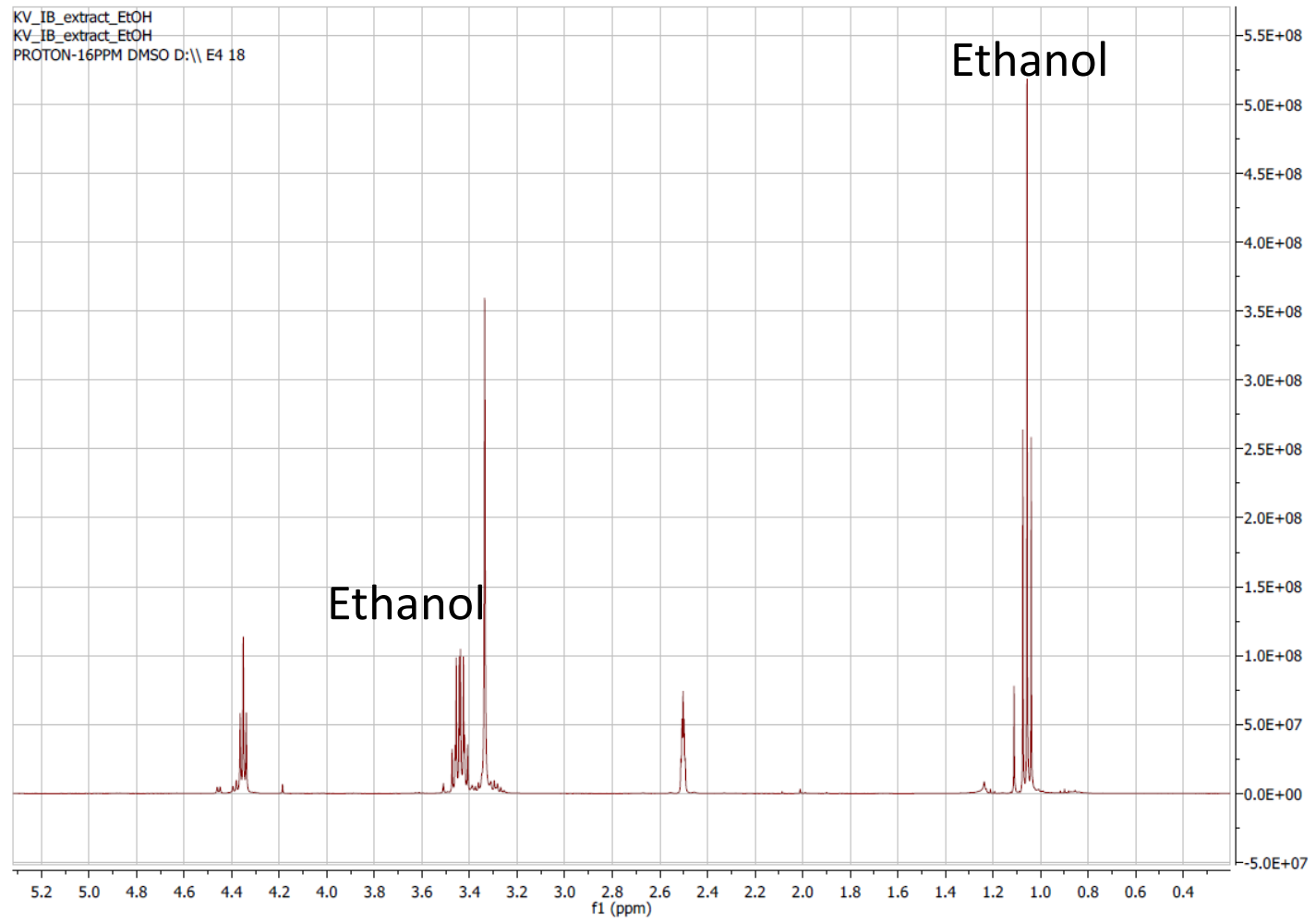

Figure S13: extraction of adsorbed compounds with ethanol. ${ }^{1} \mathrm{H}$ NMR analysis. 


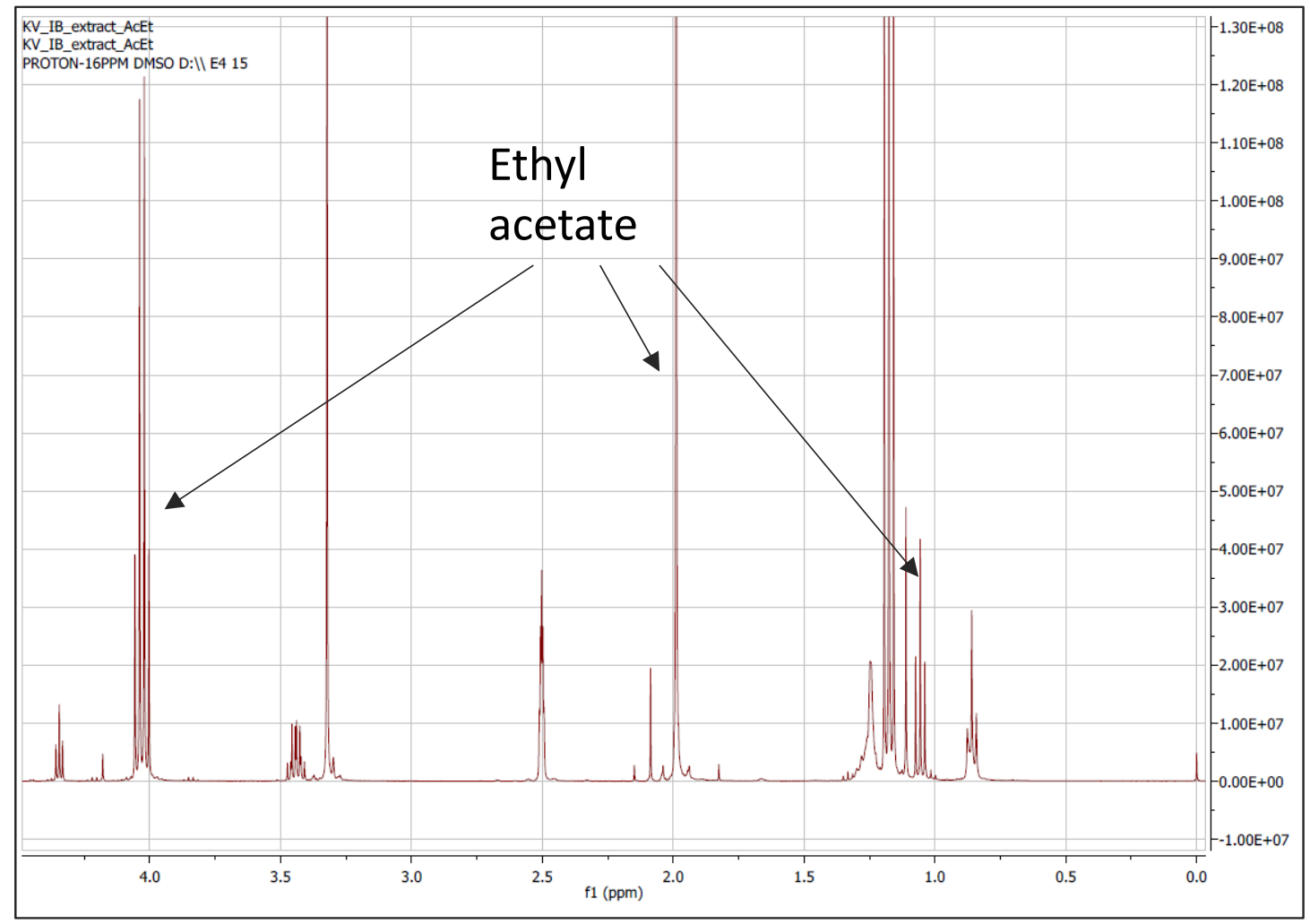

Figure S14: extraction of adsorbed compounds with ethyl acetate. ${ }^{1} \mathrm{H}$ NMR analysis.

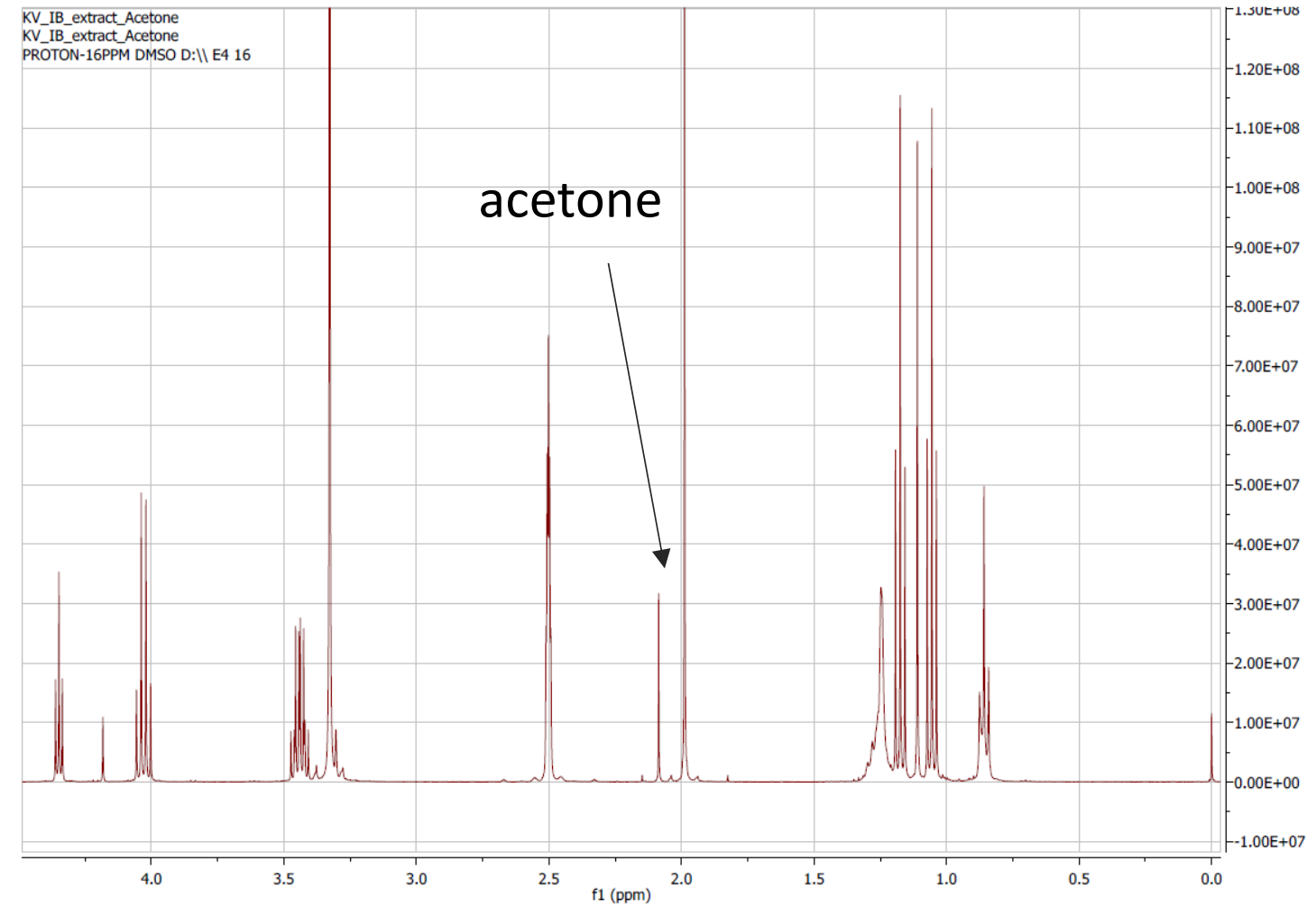

Figure S15: extraction of adsorbed compounds with acetone. ${ }^{1} \mathrm{H}$ NMR analysis. 


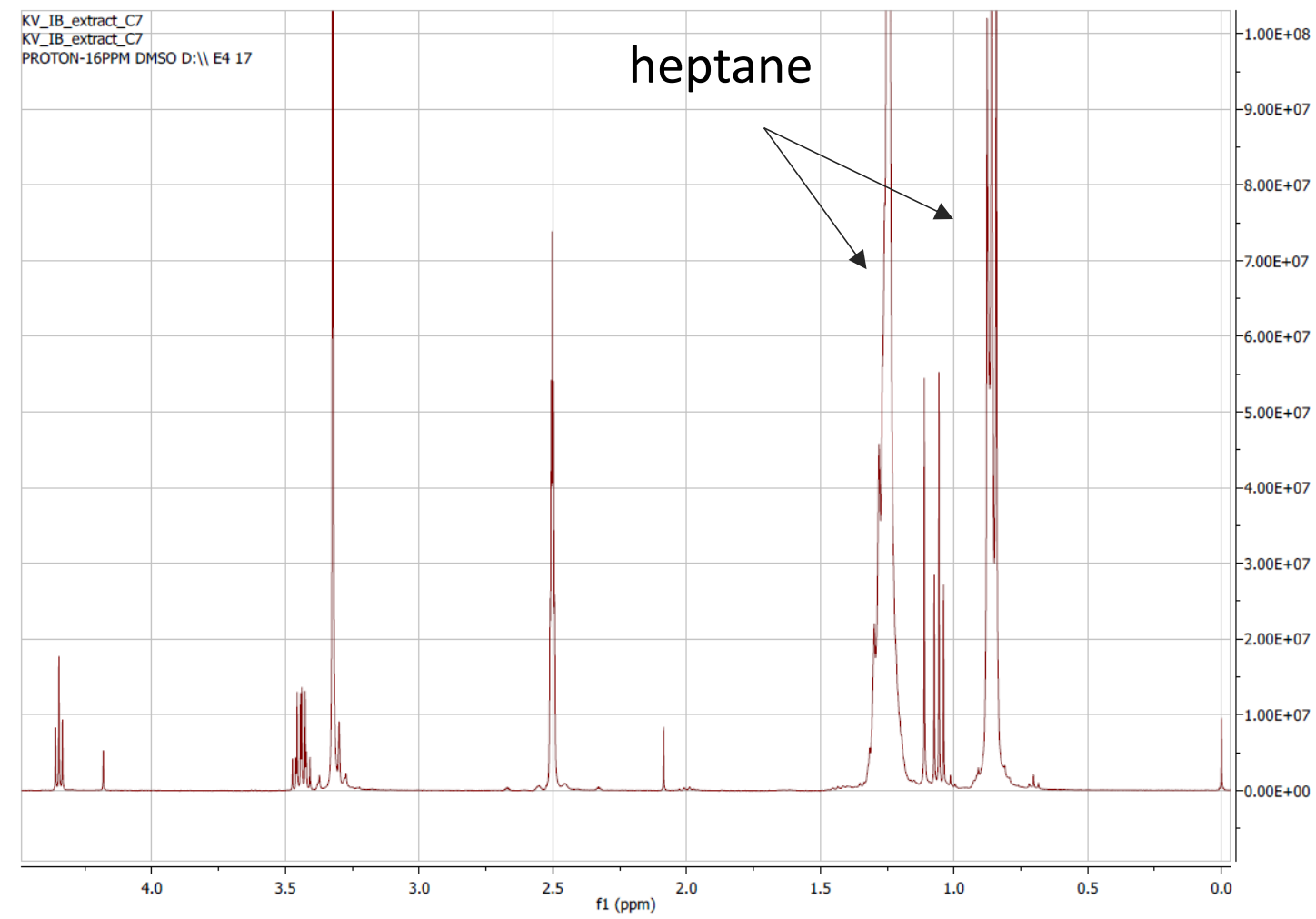

Figure S16: extraction of adsorbed compounds with heptane. ${ }^{1} \mathrm{H}$ NMR analysis.

\section{Galactitol}

${ }^{1} \mathrm{H}$ NMR spectra of galactitol were recorded on a Bruker Ultrashield $500 \mathrm{MHz}$ in deutered $\mathrm{D}_{2} \mathrm{O}$ solvent.

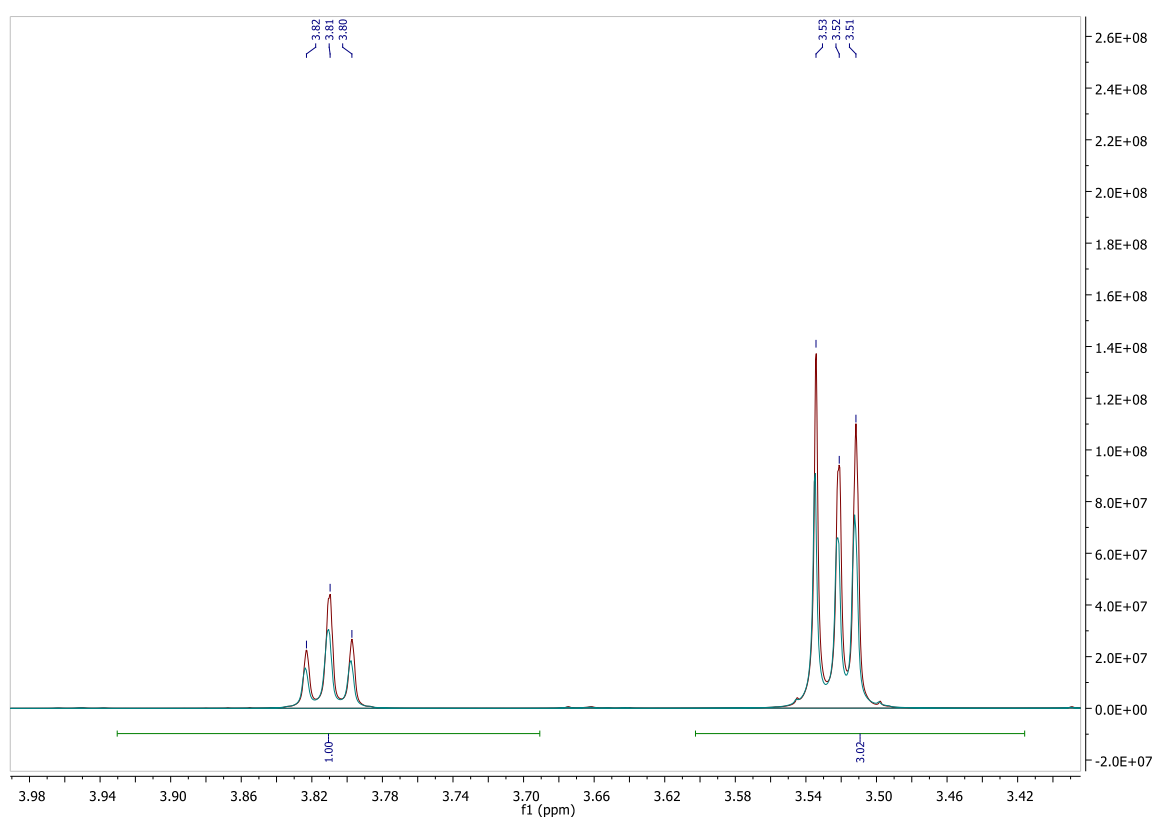

Fig. S17. Comparison of NMR profiles between pure galactitol (red) and solid product obtained after hydrogenation of galactose in presence of $\mathrm{Ru} / \mathrm{Al}_{2} \mathrm{O}_{3}$ under 30 bar of $\mathrm{H}_{2}$ at $120^{\circ} \mathrm{C}$ for $2 \mathrm{~h}$ (green). 